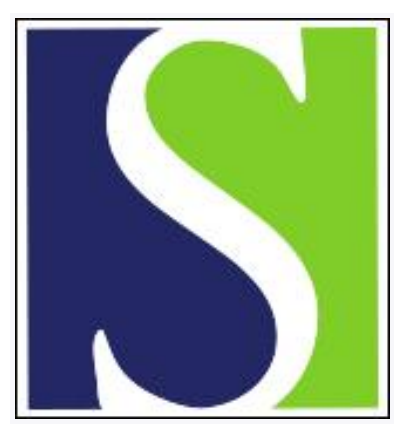

Scand J Work Environ Health 2005;31(4):258-265

https://doi.org/10.5271/sjweh.881

Issue date: Aug 2005

Seat inclination, use of lumbar support and low-back pain of taxi drivers

by Chen J-C, Tigh Dennerlein J, Chang C-C, Chang W-R, Christiani DC

Affiliation: Occupational Health Program, Harvard School of Public Health, Room 1402, HSPH-1, 655 Huntington Avenue, Boston, MA 02115, USA.

Key terms: automobile driving; epidemiology; low-back pain; lumbar support; occupational exposure; seat inclination; sitting posture; taxi driver

This article in PubMed: www.ncbi.nlm.nih.gov/pubmed/16161708 


\title{
Seat inclination, use of lumbar support and low-back pain of taxi drivers
}

\author{
by Jiu-Chiuan Chen, MD, ${ }^{1,3}$ Jack Tigh Dennerlein, PhD, ${ }^{1,2}$ Chien-Chi Chang, PhD, ${ }^{4}$ Wen-Ruey Chang, \\ PhD, ${ }^{4}$ David C Christiani, MD ${ }^{1}$
}

\begin{abstract}
Chen J-C, Tigh Dennerlein J, Chang C-C, Chang W-R, Christiani DC. Seat inclination, use of lumbar support and low-back pain of taxi drivers. Scand J Work Environ Health 2005;31(4):258-265.
\end{abstract}

\begin{abstract}
Objectives Epidemiologic evidence supporting optimal seating is limited and inconsistent. This cross-sectional study was conducted to examine the association between seat inclination, use of lumbar support, and the prevalence of clinically significant low-back pain among taxi drivers

Methods A digital inclinometer was used to measure inclinations of seat surfaces $\left(\theta_{\text {seat }}\right)$ and backrests $\left(\theta_{\text {back }}\right)$, and calculate the back-to-thigh angle $\left(\theta_{\text {back-thigh }}\right)$. Structured interviews were conducted to gather information on the use of lumbar support and the prevalence of low-back pain that had led to medical attention or absence from driving in the past month. A multiple logistic regression analysis was used to estimate the prevalence odds ratio (OR) with adjustment for age, body mass index, professional seniority, monthly driving hours, and the intensity of exposure to whole-body vibration.

Results Among 224 drivers, the mean $\theta_{\text {seat }}$ and $\theta_{\text {backrest }}$ were 14.5 (SD 9.6) and 95.1 (SD 2.7) degrees, respectively, resulting in $\theta_{\text {back-thigh }}$ of 80.6 (SD 9.3) degrees. Fifty-five percent used a lumbar support regularly, but $25 \%$ reportedly had significant low-back pain. The prevalence of low-back pain was $23 \%$ among those with $\theta_{\text {back-thigh }}<86$ degrees, $37 \%$ for those with a $\theta_{\text {back-thigh }}$ of $86 \sim 91$ degrees, and $9 \%$ for a $\theta_{\text {back-thigh }}$ of $>91$ degrees. The adjusted OR comparing those with a $\theta_{\text {back-thigh }}$ of $\leq 91$ degrees to those with a $\theta_{\text {back-thigh }}$ of $>91$ degrees was 5.11 [95\% confidence interval $(95 \% \mathrm{CI})$ 1.07 24.4]. For regularly using drivers versus those not using lumbar support, the prevalence of low-back pain was $18 \%$ versus $34 \%$, with an adjusted OR of 0.33 (95\% CI $0.16 \sim 0.68)$. Neither $\theta_{\text {seat }}$ nor $\theta_{\text {backrest }}$ alone was significantly associated with low-back pain.

Conclusions The epidemiologic observation of this study was consistent with the results of prior biomechanical studies on appropriate seat inclinations and the use of lumbar support. Prospective studies are needed to confirm the true beneficial effects of these seating parameters.
\end{abstract}

Key terms automobile driving; epidemiology; occupational exposure; sitting posture.

For decades, automobile driving (1-4) has been identified consistently as an activity associated with a variety of low-back disorders. Professional drivers operating various kinds of vehicles have been found to have high risks for sciatica $(5,6)$, intervertebral disc displacement $(2,6)$, lumbar spine degeneration $(7,8)$, and nonspecific low-back pain $(6,9,10)$. Many occupational factors, such as whole-body vibration $(4,6)$, prolonged seating posture $(6,11)$, back injury (7), and psychosocial factors $(10,12)$, have been postulated to be important determinants of drivers' low-back disorders. Although sitting while driving is not equivalent to sedentary sitting at work, many experimental studies have investigated the links of seating posture to low-back disorders. For instance, earlier studies with in vivo measurements have indicated that sitting without lumbar support and a backrest could increase disc pressure (13-15) and the electromyogrphic activities of back muscles $(16,17)$. To some extent, these biomechanical findings may have led to the widespread belief that prolonged seating posture

1 Occupational Health Program, Department of Environmental Health, Harvard School of Public Health, Boston, Massachusetts, United States.

2 Occupational Biomechanics Laboratory, Department of Environmental Health, Harvard School of Public Health, Boston, Massachusetts, United States.

3 Department of Epidemiology, School of Public Health, University of North Carolina, Chapel Hill, North Carolina, United States.

4 Liberty Mutual Research Institute for Safety, Hopkinton, Massachusetts, United States.

Correspondence to: Dr David C Christiani, Occupational Health Program, Harvard School of Public Health, Room 1402, HSPH-1, 655 Huntington Avenue, Boston, MA 02115, USA. [E-mail: dchristi@hsph.harvard.edu] 
is harmful to the lumbar spine. In some medical texts $(18,19)$ and reviews $(20-22)$, sedentary work with sitting was also classified as a risk factor for low-back pain.

However, so far, the postulated harmful effects and biomechanical disadvantages resulting from prolonged seating postures have not been fully supported by available epidemiologic data. In a recent critical review (23) of epidemiologic studies on sitting at work in relation to low-back pain published between 1985 and 1997, researchers did not find sufficient epidemiologic evidence to support the pervasive opinion that sitting while at work is associated with low-back pain. Although an interesting observation, we speculate that these inconsistent results may be caused, in part, by the way sitting at work was characterized. Often occupational epidemiologists assessed prolonged seating either through a qualitative description of job titles (sedentary versus nonsedentary) and tasks performed (eg, sedentary work versus others) or simply quantified the duration of sitting at work without knowing the exact seating posture. The awkward seating posture was mostly measured by subjective evaluation. Any of the aforementioned methods for assessing prolonged sitting posture will result in significant measurement errors sufficient to account for the observed lack of association between sitting and lowback pain.

The inconsistency between epidemiologic studies and biomechanical findings does not alter the public's perception that better seating postures can reduce the risk of back disorders. In fact, investigators have examined several seating parameters and attempted to provide guidelines for the "optimal" workstation and seat design and "ideal" sitting postures (24-28). These seating parameters include backrest inclination, seat-surface inclination, lumbar support, trunk-to-thigh angle, and knee flexion angle, among other factors. It was found that a backward inclination of the backrest decreased both the electromyographic activities of back muscles and the transdiscal pressure (13), but increased the degree of lumbar lordosis (29). The use of lumbar support was found to have biomechanical benefits similar to those of backrest inclination (30). Findings from these studies on seating parameters have helped to construct an ideal spinal model for seat design (24-26). Although these guidelines are common practices in designing office chairs and car seats, epidemiologic data supporting these biomechanical recommendations for preventing low-back pain are sparse.

The purpose of our study was to examine whether seat inclination and the use of lumbar support were associated with the prevalence of low-back pain in an epidemiologic study on urban taxi drivers. Our null hypothesis was that these seating parameters have no relation to the prevalence of low-back pain.

\section{Study population and methods}

Our study was carried out in parallel with the Taxi Drivers' Health Study, an epidemiologic study on taxi drivers in Taipei City, Taiwan. The major research interests of the study included cardiovascular diseases, job stress, low-back disorders, and a benchmark comparison of occupational health status with other occupational groups. The data for our analysis came from an exposure assessment study, nested within the Taxi Drivers' Health Study, in which we conducted a direct measurement of whole-body vibration. Figure 1 displays the construct of the Taxi Drivers' Health Study and the interrelation of its components. The study protocol was approved by the Harvard School of Public Health Human Subjects Committee and by the Institutional Review Committee of the Liberty Mutual Research Institute for Safety.

Details of the study design and sampling scheme of the full study have been reported elsewhere (31-33). In brief, a representative sample of 247 drivers was recruited from large cab companies, taxi cooperatives, cab service radio stations, and local unions to participate between June and August in 2000. The recruited study participants were all (i) male, (ii) registered professional taxi drivers, (iii) active drivers, and (iv) operating vehicles made by Toyota, Nissan, Honda, or Ford. These four manufacturers made approximately $85 \%$ of all automobiles used in Taiwan's cab business.

The population demographic features, personal characteristics, and occupational factors of the 224 drivers in our study are summarized in table 1 . The mean age was 44.6 (SD 8.2) years. On the average, they drove 188

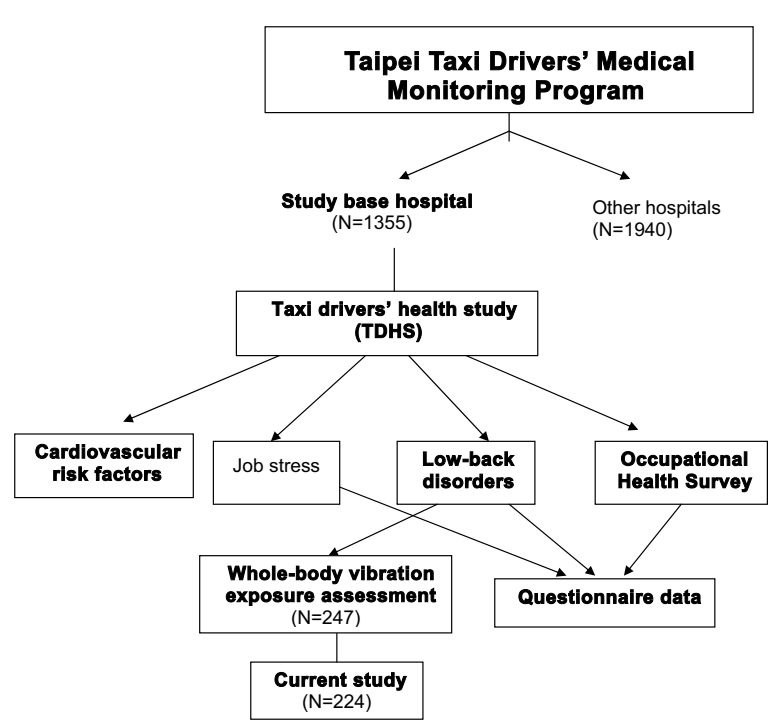

Figure 1. Structure of the Taxi Drivers' Health Study and the interrelation of its component studies. Twenty-three drivers with a significant low-back disorder before entering the taxicab business were excluded from the current study. 
Table 1. Characteristics of the 224 drivers included in the study on the effect of seat inclination and the use of lumbar support on the prevalence of low-back pain (low-back pain that had led to medical attention or absence from driving in the past month). (TDHS $=$ Taxi Drivers' Health Study)

\begin{tabular}{|c|c|c|c|c|c|c|c|c|c|c|c|c|}
\hline \multirow[t]{2}{*}{ Characteristics } & \multicolumn{2}{|c|}{$\begin{array}{c}\text { Age } \\
\text { (years) }\end{array}$} & \multicolumn{2}{|c|}{$\begin{array}{c}\text { Body mass } \\
\text { index } \\
\left(\mathrm{kg} / \mathrm{m}^{2}\right)\end{array}$} & \multicolumn{2}{|c|}{$\begin{array}{l}\text { Professional } \\
\text { seniority } \\
\text { (years) }\end{array}$} & \multicolumn{2}{|c|}{$\begin{array}{l}\text { Average days } \\
\text { of driving per } \\
\text { month (days) }\end{array}$} & \multicolumn{2}{|c|}{$\begin{array}{l}\text { Daily driving } \\
\text { duration } \\
\text { (hours) }\end{array}$} & \multicolumn{2}{|c|}{$\begin{array}{l}\text { Daily driving } \\
\text { distance } \\
(\mathrm{km})\end{array}$} \\
\hline & Mean & SD & Mean & SD & Mean & SD & Mean & SD & Mean & SD & Mean & SD \\
\hline Drivers in current study $(\mathrm{N}=224)$ & 44.6 & 8.2 & 24.7 & 3.7 & 9.3 & 7.4 & 25.8 & 2.8 & 9.7 & 2.3 & 188.0 & 53.4 \\
\hline Drivers in TDHS $(\mathrm{N}=1242)$ & 44.5 & 8.7 & 24.9 & 3.6 & 11.4 & 7.8 & 26.2 & 2.6 & 9.8 & 2.8 & . & . \\
\hline Reference a $(\%)$ & \multicolumn{2}{|c|}{43.9} & & \multicolumn{2}{|c|}{9.2} & \multicolumn{2}{|c|}{26.8} & \multicolumn{2}{|c|}{10} & \multicolumn{2}{|c|}{181.6} \\
\hline
\end{tabular}

a From the Department of Statistics, Taiwan Ministry of Transportation and Communication, Taiwan (34).

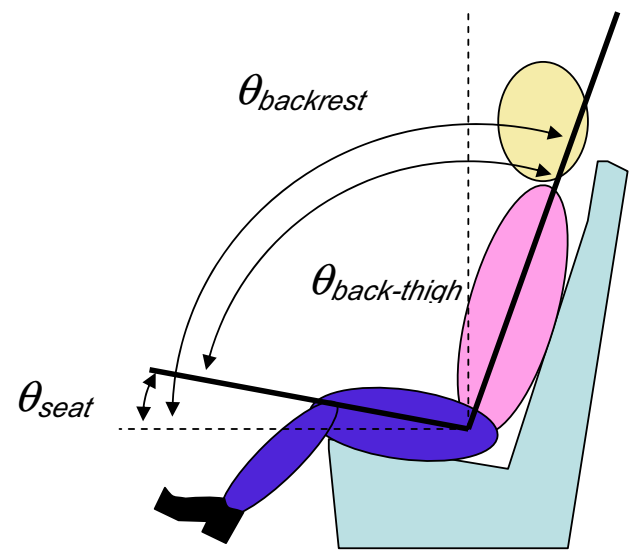

Figure 2. Measured inclinations for the seat surface $\left(\theta_{\text {seat }}\right)$ and backrest $\left(\theta_{\text {backrest }}\right)$ relative to the horizontal. These angles were measured while the driver remained seated, and the back-to-thigh angle $\left(\theta_{\text {back-thigh }}\right)$ was calculated as the difference between $\theta_{\text {backrest }}$ and $\theta_{\text {seat. }}$.

(SD 53.4) kilometers in 9.7 (SD 2.3) hours per day, and had been professional taxi drivers for 9.3 (SD 7.4) years. With respect to age, body mass index, professional seniority, driving-time profiles, daily driving distance, measured seat inclinations, and the use of lumbar support, these 224 drivers did not significantly differ from those excluded from our study because of prior lowback pain and missing covariate information. Table 1 also shows that the age, body mass index, and drivingtime profiles of those included in our study were very similar to the population characteristics of the Taxi Drivers' Health Study, although the population of the latter enrolled more professionally senior drivers, largely due to the difference in inclusion criteria. With respect to age, professional seniority, daily driving distance, and driving-time profiles, those enrolled in this study were also very comparable with the reference statistics retrieved from a nationwide survey (34) on taxi drivers in Taiwan.

We used a Pro 3600 Digital Protractor (Applied Geomechanics, Santa Cruz, CA, USA) to measure both the inclinations of the seat-surface upward $\left(\theta_{\text {seat }}\right)$ and the backrest backward $\left(\theta_{\text {backrest }}\right)$. The accuracy and standard deviation of this digital inclinometer has been specified by the manufacturer as 0.05 degrees for $0 \sim 10$ degrees,
0.10 degrees for $80 \sim 90$ degrees, and 0.20 degrees for $10 \sim 80$ degrees. The validity testing performed in our laboratory indicated a less than $1 \%$ absolute measurement error $(0 \sim 0.7 \%)$. Before any measurement was started, we verbally assured that the observed seat inclinations were the usual conditions for their seating behind the wheel. The measurement of these two inclinations was taken under loaded conditions at the end of the session measuring whole-body vibration when drivers remained seated behind the wheel and assumed the same driving postures. We did not measure spinal curvature directly because neither conventional radiograms for static posture measurement nor sophisticated motionbased methods for dynamic posture assessment are feasible tools in large epidemiologic studies enrolling hundreds to thousands of professional drivers. Instead, we calculated the difference between $\theta_{\text {backrest }}$ and $\theta_{\text {seat }}$, referred to as the back-to-thigh angle $\left(\theta_{\text {back-thigh }}\right)$, to approximate the trunk-to-thigh angle. The interrelation of these three measures $\left(\theta_{\text {backrest }}, \theta_{\text {sea }}\right.$ and $\left.\theta_{\text {back-thigh }}\right)$ is illustrated in figure 2. All the field measurements were carried out by the same investigator, and the test-retest reliability, as assessed by the intraclass correlation coefficient of two repeated tests, was 0.85 [95\% confidence interval $(95 \% \mathrm{CI}) 0.72 \sim 0.98)$ for measuring $\theta_{\text {seat }}$ and 0.92 (95\% CI $0.83 \sim 1.00$ ) for measuring $\theta_{\text {backrest }}$. None of the participating drivers complained of any discomfort during the measurement session.

The use of lumbar support was recorded by the same interviewer and confirmed through the interview process. Using a structured interview, the same interviewer also gathered individual information on demographic features, body weight and height, and driving-time profiles. At the end of the interview, each driver was asked whether he had clinically significant low-back pain, which was defined as low-back pain that had led to medical attention or an absence from driving in the past month.

In addition, we collected information on professional seniority, vehicle manufacturer, year of make, and engine size from the records on the registered licenses. Information on the average days of driving per month and average daily driving duration was obtained either from a driving diary recording, if available, or from 
self-reports. In addition, we took direct measurements of the waist and hip circumferences, wheelbase length, and tire width. The average intensity of the whole-body vibration (in root mean square) used in the final analysis was based on a statistical model that we developed to predict the individual exposure to whole-body vibration given our knowledge of average driving speed, vehicle manufacturers, year of make, engine size, professional seniority, body weight, daily driving-time profiles, wheelbase length, and use of additional cushion on the seat surface. We have documented elsewhere that the predicted exposures to whole-body vibration by our statistical model would result in an acceptable predictive validity and appraised construct validity (33).

We employed a multiple logistic regression to estimate the prevalence odds ratio (OR) of low-back pain associated with the different degrees of $\theta_{\text {seat }}, \theta_{\text {backrest }}$, and $\theta_{\text {back-thigh }}$, and the use of lumbar support. In the univariate analysis, drivers were first divided into 10 categories, according to the decile distribution of the measured and calculated inclinations. Using the subgroup with theoretically the least biomechanical stress as the reference group, we grouped together those categories with similar odds ratios for additional adjusted analyses. For a covariate to be included in the multiple logistic model, it had (i) to be a biomechnically or biologically plausible risk factor for low-back pain, (ii) its entry into the base model should have caused at least $10 \%$ change of the odds ratio associated with the change in seat inclination or the use of lumbar support, or (iii) the P-value for testing its association with low-back pain should be less than 0.25 in the univariate analysis. Drivers who reportedly had significant low-back pain $(\mathrm{N}=23)$ before entering the taxicab business were excluded, and the final multiple logistic regression only included those with complete data information. To assess the model fitting, we used the Hosmer-Lemeshow goodness-of-fit test.

All of the statistical analyses were carried out with the STATA 7.0 statistical software (STATA Corporation, College Station, TX, USA).

\section{Results}

Figure 3 depicts the distribution of the measured seat inclinations. The average inclination was 14.5 (SD 9.6) degrees for $\theta_{\text {seat }}$ and 95.2 (SD 2.7) degrees for $\theta_{\text {backrest }}$. The $\theta_{\text {back-thigh }}$ was thereby calculated as 80.7 (SD 9.3) degrees. The $\theta_{\text {back-thigh }}$ was negatively correlated with the $\theta_{\text {seat }}$ (Pearson $\left.r-0.96, \mathrm{P}<0.0001\right)$, but there was only a minor correlation between the $\theta_{\text {seat }}$ and $\theta_{\text {backrest }}$ (Pearson $r$ 0.26; $\mathrm{P}=0.0001)$. The $\theta_{\text {seat }}$ accounted for $92 \%$ of the variance of $\theta_{\text {back-thigh }}$, whereas only less than $1 \%$ of the variance of $\theta_{\text {back-thigh }}$ was explained by $\theta_{\text {backrest }}$.

A total of 56 (25\%) of the 224 drivers reported having low-back pain that had led to medical attention or absence from driving in the past month. This low-back pain prevalence did not differ from the estimated lowback pain frequency of all the participants in the Taxi Driver Health Study. According to the decile distribution of the seat inclination and the result of the univariate analysis, we grouped the drivers into the three $\theta_{\text {back-thigh }}$ categories of 53 85 degrees $(\mathrm{N}=140)$, 86 91 degrees $(\mathrm{N}=58)$, and $>91$ degrees $(\mathrm{N}=26)$. For those with a $\theta_{\text {back-thigh }}$ of 53 85 degrees, 86 91 degrees, and $>91$ degrees, the corresponding prevalence of lowback pain was $23 \%, 37 \%$, and $9 \%$ respectively. The odds ratio for having clinically significant low-back pain was $2.92(95 \%$ CI $0.65 \sim 13.2)$ in a comparison of
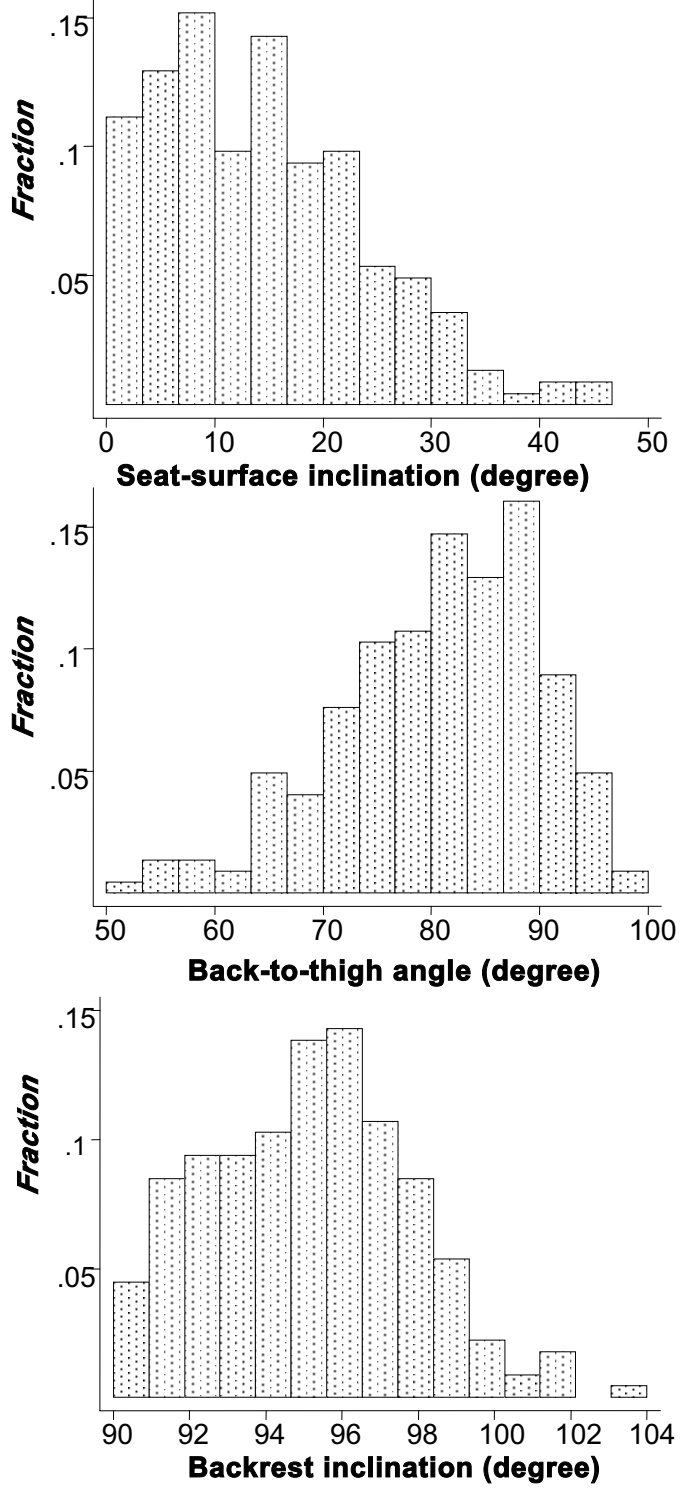

Figure 3. Distribution of the seat-surface inclination, backrest inclination, and back-to-thigh angle. 
drivers with a $\theta_{\text {back-thigh }}$ of 53 85 degrees with drivers with a $\theta_{\text {back-thigh }}$ of $>91$ degrees, whereas the odds ratio was 6.00 (95\% CI 1.27 28.3) in a comparison of drivers with a $\theta_{\text {back-thigh }}$ of 86 91 degrees with drivers with a $\theta_{\text {back-thigh }}$ of $>91$ degrees. The wide confidence interval of the odds ratio estimates resulted mainly from the small number of participants $(\mathrm{N}=26)$ within the selected reference category, which presumably had the least biomechanical stress (ie, $\theta_{\text {back-thigh }}$ of $>91$ degrees).

Altogether $55 \%$ of the drivers used a lumbar support regularly in their daily driving work. Most of the lumbar supports were simply commercialized cushion pads or pillows made of different materials, but their positions could be easily adjusted to individual preference. For those using a lumbar support in daily practice, the prevalence of low-back pain was $18 \%$, as opposed to $34 \%$ for those who did not use a lumbar support (crude OR 0.43, 95\% CI 0.23 0.81).

The results of the multiple logistic regression model, which included only 216 participants with complete data information but without significant prior low-back pain, are shown in table 2. After adjustment for age, body mass index, professional seniority, monthly driving hours, the predicted average daily intensity of whole-body vibration, and the use of a lumbar support, the adjusted odds ratio for having clinically significant low-back pain was 4.01 (95\% CI $0.82 \sim 19.5)$ in a comparison of drivers with a $\theta_{\text {back-thigh }}$ of 53 85 degrees

Table 2. Results of the multiple logistic regression a for estimating the prevalence odds ratio $(\mathrm{OR})$ for the low-back pain in association with the degrees of seat inclination, use of lumbar support, and driving time among taxi drivers. $(95 \% \mathrm{Cl}=95 \%$ confidence interval)

\begin{tabular}{|c|c|c|c|c|c|c|}
\hline Factors & $\mathrm{N}$ & $\begin{array}{l}\text { Preva- } \\
\text { lence }{ }^{b} \\
(\%)\end{array}$ & $\begin{array}{c}\text { Crude } \\
\text { preva- } \\
\text { lence } \\
\text { OR }\end{array}$ & $95 \% \mathrm{Cl}$ & $\begin{array}{c}\text { Adjusted } \\
\text { preva- } \\
\text { lence } \\
\mathrm{OR}^{\mathrm{c}}\end{array}$ & $95 \% \mathrm{Cl}$ \\
\hline \multicolumn{7}{|c|}{ Back-to-thigh angle } \\
\hline $\begin{array}{l}>91 \text { degrees } \\
86-91 \text { degrees } \\
53-85 \text { degrees }\end{array}$ & $\begin{array}{r}26 \\
58 \\
140\end{array}$ & $\begin{array}{r}9 \\
37 \\
23\end{array}$ & $\begin{array}{l}1.00 \\
6.00^{d} \\
2.92\end{array}$ & $\begin{array}{l}1.27-28.3 \\
0.65-13.2\end{array}$ & $\begin{array}{l}1.00 \\
8.79 \mathrm{e} \\
4.01\end{array}$ & $\begin{array}{l}1.70-45.4 \\
0.82-19.5\end{array}$ \\
\hline \multicolumn{7}{|c|}{ Use of lumbar support } \\
\hline $\begin{array}{l}\text { No } \\
\text { Yes }\end{array}$ & $\begin{array}{l}123 \\
101\end{array}$ & $\begin{array}{l}34 \\
18\end{array}$ & $\begin{array}{l}1.00 \\
0.43^{e}\end{array}$ & $0.23-0.81$ & $\begin{array}{l}1.00 \\
0.33^{e}\end{array}$ & $0.16-0.68$ \\
\hline \multicolumn{7}{|c|}{ Driving time per month (hours) } \\
\hline $\begin{array}{l}1^{\text {st }} \text { quartile } \\
2^{\text {nd }} \text { quartile } \\
3^{\text {rd }} \text { quartile } \\
4^{\text {th }} \text { quartile }\end{array}$ & $\begin{array}{l}57 \\
61 \\
52 \\
53\end{array}$ & $\begin{array}{l}16 \\
33 \\
35 \\
17\end{array}$ & $\begin{array}{l}1.00 \\
2.13 \\
2.04 \\
1.04\end{array}$ & $\begin{array}{c}\cdot \\
0.93-4.89 \\
0.78-5.36 \\
0.38-2.80\end{array}$ & $\begin{array}{l}1.00 \\
2.51 \\
2.29 \\
0.64\end{array}$ & $\begin{array}{c}\cdot \\
0.93-6.80 \\
0.82-6.39 \\
0.21-1.95\end{array}$ \\
\hline \multicolumn{7}{|c|}{$\begin{array}{l}\text { a The Hosmer-Lemeshow test for the goodness-of-fit of the final } \\
\text { adjusted model ( } P=0.75) \text {. } \\
\text { b The crude prevalence of low-back pain leading to medical attention or } \\
\text { absence from driving in past month. } \\
{ }^{\circ} \text { Adjusted for age, body mass index, professional seniority, predicted } \\
\text { average intensity of whole-body vibration, and the other factors } \\
\text { indicated in the table. } \\
d^{*} P<0.05 \text {. } \\
{ }^{* *} P<0.01 \text {. }\end{array}$} \\
\hline
\end{tabular}

with drivers with a $\theta_{\text {back-thigh }}$ of $>91$ degrees and 8.79 (95\% CI 1.70 45.4) in a comparison with drivers with a $\theta_{\text {back-thigh }}$ of 86 91 degrees with drivers with a $\theta_{\text {back-thigh }}$ of $>91$ degrees. This association was equivalent to an adjusted odds ratio of 5.11 (95\% CI 1.07 24.4) for having clinically significant low-back pain in a comparison of drivers with a $\theta_{\text {back-thigh }}$ of $\leq 91$ degrees with drivers with a $\theta_{\text {back-thigh }}$ of $>91$ degrees. In the crude analysis, the estimated odds ratio associated with seat inclination was negatively confounded by other factors, mainly by the average monthly driving duration. It appeared that drivers with a longer driving duration were inclined to adopt driving postures corresponding to larger $\theta_{\text {back-thigh }}$. After adjustment for these factors, regardless of the seat inclinations, comparing drivers using lumbar support in the driver's seat to drivers without such use, showed an adjusted odds ratio for low-back pain of 0.33 (95\% CI 0.16 0.68). No data were available to adjust for psychosocial factors and other physical activities in the multiple logistic regression.

In both the crude and the adjusted analyses, we found that neither the $\theta_{\text {backrest }}$ nor the $\theta_{\text {seat }}$ was significantly associated with the prevalence of low-back pain. The Hosmer-Lemeshow test $(\mathrm{P}=0.75)$ indicated the goodness-of-fit of the presented multiple logistic regression model.

\section{Discussion}

Our epidemiologic study provides the first analytic results conforming to prior biomechanical studies on seating parameters, which have led to recommended guidelines for optimal seat design and the use of lumbar support. In both crude and adjusted analyses, drivers with a larger $\theta_{\text {back-thigh }}$ (>91 degrees) had a lower prevalence of clinically significant low-back pain in the past month than those with a smaller $\theta_{\text {back-thigh }}$. Since both the backrest and seat-surface tilts were measured under loaded conditions with drivers assuming their usual driving postures, there should be strong coupling between a driver's back and the seat backrest and also between a driver's thigh and the seat surface. The seating posture imposed by these strong couplings would make the calculated $\theta_{\text {back-thigh }}$ a good proxy for measuring the trunkthigh angle in the field, even though we did not have direct measures. Previous biomechanical studies have shown that the curvature of lumbar lordosis was reduced as the trunk-thigh angle decreased $(35,36)$. In vivo measurements revealed a lower intradiscal pressure for seated postures maintaining the lumbar lordosis (13-14). Recent studies suggested an association between reduced lumbar lordosis and the risk of low-back pain in both cross-sectional (37) and prospective studies (38). 
The way we quantified the seating postures imposed by the joint inclination of the seat surface and the backrest indeed made our study results distinctive from previous epidemiologic studies investigating sitting while at work as a potential risk factor for low-back pain. The presented odds ratio has already been adjusted by the logistic regression modeling that incorporates the predicted intensity of the whole-body vibration and the driving duration, the latter often being used in previous studies to characterize prolonged sitting or other physical exposures associated with professional driving. It is also noteworthy that, as all of the measured backrest inclinations were greater than 90 degrees, observational methods for assessing seating postures commonly used by previous investigators would have resulted in misclassifying most drivers as having good seating postures. Had we used driving duration only or adapted the simple observation of the backrest inclination to characterize the seating postures of our study participants, we would have lost the ability to find the association between $\theta_{\text {back-thigh }}$ and the prevalence of low-back pain. As mentioned before, because sitting while driving is not equivalent to sedentary sitting at work, the potential advantage of assuming a favorable $\theta_{\text {back-thigh }}$ during driving may not be generalized to the prolonged sitting of other occupational settings. However, the idea and promise of using more quantitative methods for measuring seating postures should be transferable to other studies.

The observed negative association between the prevalence of low-back pain and the use of a lumbar support was also consistent with the results of many previous biomechanical studies. The use of a lumbar support has been shown to preserve the degree of lumbar lordosis in supported sitting, to decrease the electromyographic activities of back muscles, and to be related to lower intradiscal pressure $(29,39,40)$. The benefit of using lumbar support for the secondary prevention of back pain has also been reported (41).

Although biomechanical studies have shown that an increase in the backward inclination of a backrest could decrease both the electromyographic activities of back muscles and transdiscal pressure (13), both our crude and adjusted analyses revealed that neither the $\theta_{\text {backrest }}$ nor the $\theta_{\text {seat }}$ was significantly associated with the prevalence of low-back pain. Previous studies have suggested that an adjustable backrest incline of 100 degrees from the horizontal is the optimal inclination for designing a car driver's seat (24). We had reported that most of cab drivers in Taipei City used compact sedans (with a mean engine size of 1600 cubic centimeters and a mean wheelbase of 254 centimeters) for their taxicab business (31). As a result, drivers were confined to a relatively small space behind the wheel, where they had to assume driving postures without too much backward inclination in order to yield more room for passengers while obtaining proper vision through the windshield. Since our data contained very limited variability for the backrest inclination (with only 8 participants whose backrest inclinations were $\geq 100$ degrees from the horizontal), we were unable to find an association between low-back pain and backrest inclination. Moreover, we noted that a reclining backrest and control of the seatsurface inclination, a condition tested in many previous experimental studies, is mathematically equivalent to changing the back-to-thigh angles. Therefore, it is possible that the biomechanical responses of increasing the back-to-thigh angle may be very similar to what has been found for increasing backrest inclinations.

The lack of a significant association between monthly driving duration and the prevalence of low-back pain (table 2) needs to be interpreted cautiously. First, part of the outcome definition (low-back pain that led to medical attention or days away from work) may have affected the way drivers reported their average drivingtime profiles and thereby resulted in a misclassification of the true monthly driving duration. Second, although our analyses did not reveal a statistically significant association between driving duration and the prevalence of low-back pain, in this cross-sectional study, it is possible that those with significant low-back pain may have actually changed their driving-time profiles, which are more modifiable than other personal and occupational factors. Thus the "healthy worker effect" could partly explain the nonsignificant association and even the negative association between prolonged driving and lowback pain.

Our study also suffered from several other limitations of a cross-sectional design. Although it is implausible that seating parameters with biomechanical disadvantages (eg, a $\theta_{\text {back-thigh }}$ of $<91$ degrees, not using a lumbar support) would be secondary to the presence of recent significant low-back pain, it is still arguable that an observed strong association between a smaller $\theta_{\text {back-thigh }}$ and a high prevalence of low-back pain is not truly causal. As low-back pain is such a common musculoskeletal disorder, it may be that keeping favorable inclinations or using a lumbar support does not really prevent the occurrence of low-back pain but simply reduces the frequency of low-back pain episodes, a phenomenon reflecting the length sampling bias of crosssectional studies. In addition, the observed nonmonotone of the exposure-response relation between $\theta_{\text {back-thigh }}$ and the prevalence of low-back pain is subject to the possibility that drivers with recently significant lowback pain would have changed their seat inclinations from the mostly uncomfortable degrees ( $<86$ degrees) to less uncomfortable degrees (86 91 degrees) or even to more favorable ranges ( $>91$ degrees). A prospective study should allow us to address the methodological 
Table 3. Sensitivity of the association between the back-to-thigh angle $\left(\theta_{\text {back-thigh }}\right)$ and back pain (prevalence odds ratio $d x^{\mathrm{a}}$ ) to various combinations of the relative prevalence of an unmeasured binary confounder $z$ among those with a back-to-thigh angle of $\leq 91$ degrees $(P z 1)$ versus those with back-to-thigh angle of $>91$ degrees $(P z 0)$.

\begin{tabular}{lrrrrrr}
\hline \multirow{2}{*}{$\begin{array}{l}\text { Preva- } \\
\text { lence }\end{array} \begin{array}{c}\text { Preva- } \\
\text { lence }\end{array}$} & \begin{tabular}{c} 
Preva- \\
lence \\
\cline { 4 - 7 }
\end{tabular} & \multicolumn{5}{c}{ Prevalence odds ratio $d x$} \\
\cline { 4 - 7 } & & $\begin{array}{r}\text { odds } \\
\text { ratio } \\
x z^{\mathrm{b}}\end{array}$ & $\begin{array}{c}\text { Preva- } \\
\text { lence } \\
\text { odds } \\
\text { ratio } \\
d z^{c} 2\end{array}$ & $\begin{array}{c}\text { Preva- } \\
\text { lence } \\
\text { odds } \\
\text { ratio } \\
d z^{c} 3\end{array}$ & $\begin{array}{c}\text { Preva- } \\
\text { lence } \\
\text { odds } \\
\text { ratio } \\
d z 4\end{array}$ & $\begin{array}{c}\text { Preva- } \\
\text { lence } \\
\text { odds } \\
\text { ratio } \\
d z^{c 5}\end{array}$ \\
\hline 0.2 & 0.1 & 2.25 & 3.69 & 3.45 & 3.27 & 3.13 \\
0.3 & 0.1 & 3.86 & 3.40 & 3.02 & 2.76 & 2.56 \\
0.4 & 0.2 & 2.67 & 3.45 & 3.13 & 2.93 & 2.79 \\
0.5 & 0.25 & 3 & 3.36 & 3.02 & 2.82 & 2.69 \\
0.5 & 0.33 & 2.03 & 3.57 & 3.34 & 3.21 & 3.12 \\
0.6 & 0.3 & 3.5 & 3.27 & 2.93 & 2.73 & 2.61 \\
0.6 & 0.4 & 2.25 & 3.52 & 3.30 & 3.16 & 3.08 \\
0.7 & 0.35 & 4.33 & 3.20 & 2.85 & 2.66 & 2.54 \\
0.75 & 0.45 & 3.67 & 3.57 & 3.38 & 3.28 & 3.22 \\
0.75 & 0.55 & 2.45 & 3.34 & 3.06 & 2.91 & 2.82 \\
\hline
\end{tabular}

a The prevalence odds ratio for back pain comparing a $\theta_{\text {back-thigh }} \leq 91$ degrees witg a $\theta_{\text {back-thigh }}$ of $>91^{\circ}$.

${ }^{b}$ The prevalence odds ratio for a $\theta_{\text {back-thigh }}$ of $\leq 91$ degrees comparing those with $z=1$ to those with $z=0$.

c The prevalence odds ratio for having back pain associated to $z=1$ as compared to $\mathrm{z}=0$.

complexities and examine the true benefits of these seating parameters in preventing low-back pain.

The time and resource limitation diminished our ability to assess other risk factors of low-back pain comprehensively, such as psychosocial factors, other physical activities (lifting, bending and twisting, etc), and smoking. In terms of a mechanism, seating postures imposed by biomechanically favorable parameters may reduce the psychosocial stress associated with prolonged driving. Our empirical data from a subset of participants $(\mathrm{N}=39)$ who provided information on seat inclination and job stressors did suggest that those with a favorable inclination ( $>91$ degrees) perceived less job stress than those with an unfavorable ( $\leq 91$ degrees) inclination $(22 \%$ versus $60 \%, \mathrm{P}=0.11)$. With respect to confounding by other physical activities, our empirical data indicated that those with a $\theta_{\text {back-thigh }}$ of $>91$ degrees, as compared with those with a $\theta_{\text {back-thigh }}$ of $\leq 91$ degrees, were more involved in lifting (20\% versus $6 \%$ ) and bending and twisting occupational activities (20\% versus $10 \%)$. Although these associations did not reach statistical significance ( $\mathrm{P}=0.36$ and 0.47 , respectively), it seemed more likely that the potential negative confounding by other physical activities may have biased the association between $\theta_{\text {back-thigh }}$ and low-back pain towards the null. The possibility of positive confounding by smoking cannot be ruled out. However, the potential positive confounding by smoking, if any, is unlikely to account completely for the observed association between $\theta_{\text {back-thigh }}$ and low-back pain, as the difference in smoking prevalence between the drivers with a $\theta_{\text {back-thigh }}$ of $>91$ degrees and those with a $\theta_{\text {back-thigh }}$ of $\leq 91$ degrees was not substantial ( $67 \%$ versus $45 \%, \mathrm{P}=0.65)$.

To seek for alternative explanations for our interesting findings, we conducted further sensitivity analyses (42), attempting to determine how severe the effect of an unmeasured confounder or residual confounding, if any, would have to be to affect our results (table 3). For example, if we missed a strong low-back pain risk factor that had an odds ratio of 5.0 and was three times more prevalent ( $30 \%$, for example) among those with a $\theta_{\text {back-thigh }}$ of $\leq 91$ degrees than among those with a $\theta_{\text {back- }}$ thigh of $>91$ degrees (10\%), the odds ratio (a $\theta_{\text {back-thigh }}$ of $\leq 91$ degrees versus a $\theta_{\text {back-thigh }}$ of $>91$ degrees) would only be decreased from 4.06 to 2.56 . Given the magnitudes of the odds ratio estimates in both the crude and adjusted analyses (4.06 and 5.11 for a $\theta_{\text {back-thigh }}$ of $\leq 91$ degrees), our sensitivity analyses indicated that the reported significant association between $\theta_{\text {back-thigh }}$ and lowback pain was not merely the consequence of either residual or unadjusted confounding per se.

\section{Acknowledgments}

This study was funded by the Liberty Mutual-Harvard Pilot Project Program in Occupational Safety and Health, and also by the CDC (NIOSH) Center Grant T42 CCT110421-11.

The authors thank Mr Eric Jones and Mr Peter Teare of the Liberty Mutual Research Institute for Safety, Hopkinton, Massachusetts, USA, and Mr Ming-Jhi Tzeng and Mr Chin-Hung Yang of the Department of Biomedical Engineering of the National Taiwan University Hospital, Taipei, Taiwan, for their technical support.

\section{References}

1. Liira JP, Shannon HS, Chambers LW, Haines TA. Long-term back problems and physical work exposures in the 1990 Ontario health survey. Am J Public Health 1996;86(3):382-7.

2. Kelsey JL, Hardy RJ. Driving of motor vehicles as a risk factor for acute herniated lumbar intervertebral disc. Am J Epidemiol 1975;102(1):63-73.

3. National Institute of Occupational Safety and Health (NIOSH). Musculoskeletal disorders and workplace factors: a critical review of epidemiologic evidence for work-related musculoskeletal disorders of the neck, upper extremity, and low back. Cincinnati (OH): NIOSH; 1997. NIOSH PB:97141.

4. Bovenzi M, Hulshof CT. An updated review of epidemiologic studies on the relationship between exposure to whole-body vibration and low back pain (1986-1997). Int Arch Occup 
Environ Health 1999;72(6):351-65.

5. Heliövaara M. Occupation and risk of herniated lumbar intervertebral disc or sciatica leading to hospitalization. J Chronic Dis 1987;40(3):259-64.

6. Bovenzi M, Zadini A. Self-reported low back symptoms in urban bus drivers exposed to whole-body vibration. Spine 1992;17(9):1048-59.

7. Luoma K, Riihimäki H, Raininko R, Luukkonen R, Lamminen A, Viikari-Juntura E. Lumbar disc degeneration in relation to occupation. Scand J Work Environ Health 1998;24(5):358-66.

8. Frymoyer JW, Newberg A, Pope MH, Wilder DG, Clements $\mathrm{J}$, MacPherson B. Spine radiographs in patients with low-back pain: an epidemiological study in men. J Bone Joint Surg Am 1984;66(7):1048-55.

9. Anderson R. The back pain of bus drivers: prevalence in an urban area of California. Spine 1992;17(12):1481-8.

10. Krause N, Ragland DR, Fisher JM, Syme SL. Psychosocial job factors, physical workload, and incidence of work-related spinal injury: a 5-year prospective study of urban transit operators. Spine 1998;23(23):2507-16.

11. Krause N, Ragland DR, Greiner BA, Fisher JM, Holman BL, Selvin S. Physical workload and ergonomic factors associated with prevalence of back and neck pain in urban transit operators. Spine 1997;22(18):2117-227.

12. Netterstrøm B, Juel K. Low back trouble among urban bus drivers in Denmark. Scand J Soc Med 1989;17(2):203-6.

13. Nachemson AL. Disc pressure measurements. Spine 1981;6(1):93-7.

14. Nachemson A, Elfström G. Intravital dynamic pressure measurements in lumbar discs: a study of common movements, maneuvers and exercises. Scand J Rehabil Med Suppl 1970;1:1-40.

15. Andersson BJ, Ortengren R, Nachemson AL, Elfstrom G, Broman $\mathrm{H}$. The sitting posture: an electromyographic and discometric study. Orthop Clin North Am 1975;6(1):105-20.

16. Andersson BJ, Jonsson B, Ortengren R. Myoelectric activity in individual lumbar erector spinae muscles in sitting. A study with surface and wire electrodes. Scand J Rehabil Med Suppl 1974;3:91-108.

17. Andersson BJ, Ortengren R. Myoelectric back muscle activity during sitting. Scand J Rehabil Med Suppl 1974;3:73-90.

18. Lomax JD, Johanning E. Occupational medicine. Philadelphia (PA): Lippincott Williams \& Wilkins; 2001.

19. Rosenstock L, Cullen MR. Textbook of clinical occupational and environmental medicine. Philadelphia (PA): Saunders; 1994.

20. Andersson GB. Epidemiology of low back pain. Acta Orthop Scand Suppl 1998;281:28-31.

21. Johanning E. Evaluation and management of occupational low back disorders. Am J Ind Med 2000;37(1):94-111.

22. Phillips JA, Forrester B, Brown KC. Low back pain: prevention and management. AAOHN 1996;44(1):40-53.

23. Hartvigsen J, Leboeuf-Yde C, Lings S, Corder EH. Is sittingwhile-at-work associated with low back pain? a systematic, critical literature review. Scand J Public Health 2000;28(3):230-9.

24. Harrison DD, Harrison SO, Croft AC, Harrison DE, Troyanovich SJ. Sitting biomechanics, part II: optimal car driver's seat and optimal driver's spinal model. J Manipulative Physiol Ther 2000;23(1):37-47.

25. Harrison DD, Harrison SO, Croft AC, Harrison DE, Troyanovich SJ. Sitting biomechanics part I: review of the literature. J Manipulative Physiol Ther 1999;22(9):594-609.

26. Brunswic M. Ergonomics of seat design. Physiotherapy 1984;70(2):40-3.

27. Chaffin DB, Andersson G, Martin BJ. Occupational biomechanics. 3rd ed. New York (NY): Wiley-Interscience Publication; 1999.

28. Keegan JJ. Choosing seating for hospital patients. Hospitals 1966;40(19):72-3.

29. Andersson GB, Murphy RW, Ortengren R, Nachemson AL. The influence of backrest inclination and lumbar support on lumbar lordosis. Spine 1979;4(1):52-8.

30. Boudrifa H, Davies BT. The effect of backrest inclination, lumbar support and thoracic support on erector spinae muscles when lifting. Eur J Appl Physiol Occup Physiol 1985;54(5):538-45.

31. Chen JC, Chang WR, Shih TS, Chen CJ, Chang WP, Dennerlein JT, et al. Predictors of whole-body vibration levels among urban taxi drivers. Ergonomics 2003;46(11):1075-90.

32. Chen JC, Dennerlein JT, Shih TS, Chen CJ, Cheng Y, Chang WP, et al. Knee pain and driving duration: a secondary analysis of the taxi drivers' health study. Am J Public Health 2004;94(4):578-81.

33. Chen JC, Chang WR, Shih TS, Chen CJ, Chang WP, Dennerlein JT, et al. Using "exposure prediction rules" for exposure assessment: an example on whole-body vibration in taxi drivers. Epidemiology 2004;15(3):293-9.

34. Taiwan Ministry of Transportation and Communications (MOTC). Survey report on taxi service business. Taipei City (Taiwan): MOTC; 2000.

35. Bridger RS, Wilkinson D, van Houweninge T. Hip joint mobility and spinal angles in standing and in different sitting postures. Hum Factors 1989;31(2):229-41.

36. Yasukouchi A, Isayama T. The relationships between lumbar curves, pelvic tilt and joint mobilities in different sitting postures in young adult males. Appl Human Sci 1995;14(1):1521.

37. Tsuji T, Matsuyama Y, Sato K, Hasegawa Y, Yimin Y, Iwata H. Epidemiology of low back pain in the elderly: correlation with lumbar lordosis. J Orthop Sci 2001;6(4):307-11.

38. Adams MA, Mannion AF, Dolan P. Personal risk factors for first-time low back pain. Spine 1999;24(23):2497-505.

39. Majeske C, Buchanan C. Quantitative description of two sitting postures: with and without a lumbar support pillow. Phys Ther 1984;64(10):1531-5.

40. Bendix T, Poulsen V, Klausen K, Jensen CV. What does a backrest actually do to the lumbar spine? Ergonomics 1996;39(4):533-42.

41. Williams MM, Hawley JA, McKenzie RA, van Wijmen PM. A comparison of the effects of two sitting postures on back and referred pain. Spine 1991;16(10):1185-91.

42. Greenland S. Basic methods for sensitivity analysis of biases. Int J Epidemiol 996;25(6):1107-16.

Received for publication: 13 September 2004 